\title{
A formação de jovens do campo e o vínculo entre conhecimento, trabalho e educação: um estudo do Colégio Estadual do Campo Iraci Salete Strozak ${ }^{1}$
}

\section{The formation of rural young people and the link between knowledge, work and education: a study of Colégio Estadual do Campo Iraci Salete Strozak}

Natacha Eugênia Janata²

\begin{abstract}
RESUMO
O acesso ao conhecimento e a relação escola e vida tem sido uma temática presente nos estudos acerca da proposta educacional do Movimento dos Trabalhadores Rurais Sem Terra (MST). Neste texto abordamos a especificidade da formação de jovens do campo, considerando a relevância dessa conexão. Apresentamos dados de pesquisa de doutorado em educação que buscou compreender o entrecruzamento do trabalho, escolarização e militância de egressos de uma escola de assentamento do MST e sua relação com a formação dos jovens, sobretudo, os militantes. Para tanto, realizamos entrevistas semiestruturadas com 22 egressos, lideranças e equipe diretiva da escola, além de análise do Projeto Político-Pedagógico. Caracterizamos a instituição investigada, destacando as problemáticas acerca do acesso ao conhecimento e a relação trabalho e educação na formação dos jovens. Concluímos identificando os limites da escola, compreendendo-a no interior das relações capitalistas de produção da vida, bem como ressaltando as possibilidades que o vínculo entre trabalho e educação no acesso ao conhecimento traz para a constituição de jovens do campo que compreendem as
\end{abstract}

DOI: $10.1590 / 0104-4060.39819$

1 Pesquisa financiada por bolsa doutorado da Coordenação de Aperfeiçoamento de Pessoal de Nível Superior - CAPES no período de 03/2010 a 03/2012.

2 Universidade Federal de Santa Catarina. Florianópolis, Santa Catarina, Brasil. Centro de Ciências da Educação. Campus Universitário Trindade. CEP: 88010-970. 
contradições e se comprometem com as lutas da classe trabalhadora, em especial a do MST.

Palavras-chave: juventude; MST; trabalho; educação.

\begin{abstract}
Access to knowledge and the relation between school and life has been a theme present in studies about the educational proposal of the Landless Rural Workers Movement (Movimento dos Trabalhadores Rurais Sem Terra - MST). In this article we approach the specificity of rural youth training, considering the importance of this connection. We present data from doctoral research in education that sought to understand the interweaving of work, education and militancy of the graduates of a MST settlement school and its relation to the formation of the rural youth, primarily, the militants. For this, we conducted semi-structured interviews with 22 graduates, the leadership and school management team, and furthered the analysis of the political pedagogical project. We characterize the investigated institution, highlighting the issues about access to knowledge and the relationship between work and education in youth training. We conclude by identifying the boundaries of the school, understanding it in the general context of capitalist production, as well as emphasizing the possibilities that the link between work and education in the access to knowledge brings to the establishment of rural youths who understand the contradictions and commit themselves to fighting for the working class cause, especially the MST.
\end{abstract}

Keywords: youth; MST; work; education.

\title{
Introdução
}

No período de 2008 a 2012 realizamos pesquisa de doutorado intitulada “"Juventude que ousa lutar!': trabalho, educação e militância de jovens assentados do MST", tendo como temática a juventude do campo, especificamente oriunda de assentamento do Movimento dos Trabalhadores Rurais Sem Terra (MST), a partir de três eixos de análise, o trabalho, a escolarização e a militância. O lócus da investigação foi o Colégio Estadual do Campo Iraci Salete Strozak, localizado em um assentamento do MST no Paraná ${ }^{3}$, tendo como foco os jovens

3 O Assentamento Marcos Freire, município de Rio Bonito do Iguaçu-PR. Este assentamento foi fruto da luta pela terra e de umas das maiores ocupações realizadas no Paraná em 1996. 
egressos do Ensino Médio ou do Médio Integrado - Curso de Formação de Docentes para a Educação Infantil e Anos Iniciais dessa instituição. O objetivo geral foi compreender o entrecruzamento entre trabalho, escolarização e militância dos egressos do nível médio dessa escola e sua relação com a formação dos jovens dos assentamentos, em específico dos militantes do MST. Neste texto apresentamos sínteses reflexivas acerca da potencialidade da relação entre conhecimento, trabalho e educação na formação dos jovens, tomando como base a sistematização da investigação.

Os egressos do Colégio Iraci ${ }^{4}$ considerados foram do período de 2001 (ano em que se formou a primeira turma) e 2009 (ano em que se iniciou a pesquisa exploratória). Como o Curso de Formação de Docentes - nível médio teve seu início mais tardiamente, apenas foram considerados os anos de 2008 (em que se formou a primeira turma) e 2009. Dessa forma, havia um conjunto de 138 egressos, dos quais 114 do Ensino Médio e 24 do Curso de Formação de Docentes - nível médio. Dos 22 jovens entrevistados, 15 haviam cursado o Ensino Médio e os demais o Curso de Formação de Docentes - nível médio. Buscou-se garantir uma amplitude de sujeitos em relação aos eixos de análise. O universo das 22 entrevistas abrangeu jovens que ainda moravam no assentamento e que já haviam mudado de residência; jovens que trabalhavam no assentamento, em outros locais ou estavam desempregados; jovens que prosseguiram os estudos, acessando o nível superior e que haviam parado de estudar; por fim, jovens militantes do MST, de outros movimentos/organizações sociais ou não militantes.

No percurso metodológico foram realizadas entrevistas semiestruturadas: na fase exploratória, no formato de grupo focal com oito jovens e, posteriormente, de forma individual com os demais. Houve também a observação participante na II Jornada Nacional da Juventude do MST, evento realizado de 8 a 11/08/2011, em Rio Bonito do Iguaçu, no Centro de Desenvolvimento Sustentável e Capacitação em Agroecologia (CEAGRO). Entrevistas com lideranças, direção e coordenação pedagógica da escola, bem como a análise do Projeto Político-Pedagógico - PPP também fizeram parte da investigação.

Apresentamos a seguir dados gerais sobre a escola pesquisada, que são o ponto de partida para a posterior reflexão acerca do vínculo entre conhecimento, trabalho e educação na formação dos jovens do campo, no sentido estrito, porém ampliando para toda juventude trabalhadora.

4 Denominação utilizada pelos entrevistados e adotada ao longo do texto para permitir melhor fluxo na leitura. 


\section{Colégio Estadual do Campo Iraci Salete Strozak: breve caracterização}

Os anos 1990 foram marcados pelas reformas educacionais resultantes dos ajustes da economia brasileira à reestruturação mundial. (SHIROMA; MORAES; EVANGELISTA, 2004). Sob as exigências de uso racionalizado dos recursos nos mais diferentes setores estatais, as escolas multisseriadas presentes nas comunidades dos pequenos municípios foram fechadas e centralizadas. $\mathrm{O}$ transporte escolar foi assumido como uma política de contenção nos gastos com a educação pública. No Paraná, o governo de Jaime Lerner buscou seguir à risca as indicações das agências multilaterais de financiamento para a educação, garantindo os acordos e empréstimos que determinaram as medidas tomadas nos diferentes níveis de ensino. (SAPELLI, 2008).

O percurso de conquista das escolas no assentamento em que se insere nossa investigação iniciou quando as famílias estavam acampadas na beira da estrada, período anterior à ocupação da fazenda da madeireira Giacomet-Marodin ${ }^{5}$, em rio Bonito do Iguaçu, PR. Nesse momento, a solução encontrada foi o transporte dos estudantes para as escolas na sede do município ${ }^{6}$, tanto estadual como municipal.

Com o assentamento de um contingente de aproximadamente 1.500 famílias, a luta por escola mobilizou pais, jovens e crianças no intuito de garantir o acesso à escolarização, bem como a possibilidade de uma formação diferenciada. A escola passou a configurar-se num importante espaço formativo. Essa tem sido uma característica que vem acompanhando a trajetória da educação e da escola no MST, como já abordado nas primeiras reflexões sobre a temática, por Caldart e Schwaab (1991); Caldart (1986) e mais recentemente por Dalmagro (2010).

A desapropriação de uma primeira parte da fazenda fortaleceu a busca por conquistar escolas no interior do assentamento, resultando na criação, em meados de 1997, da Escola Rural Municipal Vanderlei das Neves ${ }^{7}$, atendendo aos anos iniciais do Ensino Fundamental e da Escola Estadual José Alves dos Santos ${ }^{8}$, com os anos finais do mesmo nível de ensino.

5 Empresa que possuía em 1996, ano da ocupação do MST, uma área de aproximadamente 80 mil hectares, numa extensão que envolvia três municípios paranaenses, entre eles Rio Bonito do Iguaçu. No local onde antes havia a exploração da terra para uso de apenas uma única família, passou-se a produzir vida para cerca de 1.500 famílias.

6 Iraci Salete Strozak, em depoimento a Rodrigues (1999), relatou que nos dois primeiros meses da ocupação funcionaram escolas de barracos na beira do asfalto, com professores voluntários do próprio acampamento. Como foi insuficiente, negociaram para que as crianças fossem estudar na escola do município.

7 Segundo Resolução 1.950/97, publicada em Diário Oficial do Estado em 27/06/1997.

8 Segundo Resolução 1.969/97, publicada em Diário Oficial do Estado em 05/06/1997. 
Com a desapropriação de mais uma parte da fazenda, as famílias se espalharam pelos lotes e passaram a ocupar cerca de 26 mil hectares, aumentando as distâncias a serem percorridas até a localização das somente duas escolas existentes. Nesse contexto, apresenta-se o Colégio Estadual Iraci Salete Strozak, originariamente como extensão da Escola Estadual José Alves dos Santos. No início de 1999, obteve autorização de funcionamento ${ }^{9}$ constituindo-se autonomamente enquanto estabelecimento de ensino e alocando-se no Assentamento Marcos Freire. Essa conquista ocorreu após pressões, negociações e a ocupação do Núcleo de Educação de Laranjeiras do Sul, órgão descentralizado da Secretaria de Estado da Educação. Outras escolas foram criadas no assentamento, totalizando dez que permaneciam em 2010.

Com o intuito de consolidar e ampliar os avanços na educação e escolarização, o MST, através do Setor de Educação, deslocou para a região um pedagogo com a atribuição de contribuir na criação e efetivação das escolas nos Assentamentos Ireno Alves dos Santos e Marcos Freire, desde as negociações políticas até o acompanhamento pedagógico. (MONTEIRO, 2003). A elaboração dos Projetos Político-Pedagógicos das escolas do assentamento buscou garantir os princípios assumidos pelo Movimento e, além disso, foi realizado um trabalho de formação dos professores que iriam atuar e, necessariamente, não precisavam ser vinculados ao mesmo, já que eram contratados pelo Município ou Estado. Em entrevista com a vice-diretora ${ }^{10}$, verificamos que a presença desse pedagogo permanecia contribuindo na continuidade dos vínculos com as propostas educativas do MST, pela participação em momentos na formação de professores, refletindo e problematizando as práticas pedagógicas desenvolvidas.

Graças à organização coletiva e à continuidade da luta, os assentados alcançam o direito à educação escolar. Vivem a contradição de possibilitar o acesso sem, contudo, ter a qualidade necessária e almejada. Essa falta passa a ser mais um agente mobilizador dos estudantes, famílias, professores e lideranças e, por isso, um elemento de continuidade das negociações e pressões, fazendo avançar as conquistas.

Em 2010, o quadro docente e de funcionários ${ }^{11}$ da escola contava com 30 professores que atuavam nos anos finais do Ensino Fundamental, Ensino Médio e no curso de Formação de Docentes em nível médio. Destes, apenas 12 eram concursados. Os demais eram contratados temporariamente para atuação no

9 Segundo Resolução 714/99, publicada em Diário Oficial do Estado em 04/02/1999.

10 Entrevista concedida à autora em 08/07/2010.

11 Dados fornecidos durante a pesquisa de campo pela secretaria do Colégio no dia 07/07/2010. 
ano letivo corrente. Alguns fatores foram apontados pela vice-diretora ${ }^{12}$ como prováveis causas da desistência em permanecer trabalhando no Colégio Iraci, entre eles a distância percorrida e o tempo gasto diariamente com a locomoção, em torno de duas horas no trajeto de ida e volta. Nesse caso, quem arcava com os custos do deslocamento eram os professores, que, embora tenham adicional nos salários, ficavam em desvantagem se comparados com aqueles que trabalhavam na cidade e não gastavam com as passagens de ônibus.

Localizar-se em um assentamento de reforma agrária do MST também se constituía em impedimento para alguns, já que essa ligação conferia uma identidade ao Colégio Iraci e, invariavelmente, acarretava em práticas pedagógicas e compromissos políticos nem sempre convergentes com todos os que assumiam sua carga horária nele. Essa era uma problemática também para parte dos professores contratados temporariamente, que acabava ficando na escola por um ano pela necessidade financeira apenas, não se comprometendo com a instituição e, em determinados casos, até mesmo dificultando o andamento do trabalho pedagógico.

A situação se invertia no caso dos cargos administrativos que, de um total de sete funcionários, seis eram concursados, exercendo funções na secretaria, biblioteca, limpeza e merenda escolar. Desses, havia três que moravam no assentamento, outros três na sede do município e apenas uma pessoa na cidade vizinha.

A gestão da escola era composta pela direção, eleita com mandato de três anos, além do Conselho Escolar e a Associação de Pais, Mestres e Funcionários, instâncias nas quais o MST estava inserido. A escola possuía laços estreitos com a comunidade e com o próprio MST, principalmente através do Setor de Educação regional, que vinha se reestruturando há cerca de dois anos. Exemplo disso foi a realização nas suas dependências, em junho de 2010, do II Encontro da Juventude da Reforma Agrária, organizado por três assentamentos: Marcos Freire, Ireno Alves dos Santos e 10 de $\mathrm{Maio}^{13}$, todos de área desapropriada da fazenda da madeireira Giacomet-Marodin.

As relações com o MST também foram evidenciadas pela tarefa assumida a partir de 2004 de se constituir como a primeira Escola Base das Escolas Itinerantes no Estado, contribuindo para que as escolas dos acampamentos pudessem ter a estruturação de sua vida legal, com apoio pedagógico e administrativo e, em última instância, colaborando para sua viabilização. A partir de 2005, em decorrência dessa função, o Colégio Iraci passou por um processo de reestruturação curricular, reorganizando o trabalho pedagógico segundo os Ciclos de Formação Humana, conforme contribuições principalmente de Freitas (2003).

12 Entrevista concedida à autora em 08/07/2010.

13 Os Assentamentos citados compõem, dentro da organicidade interna do MST, a Brigada Ireno Alves, considerada como região centro do Estado. 
O trabalho constante de reflexão sobre o histórico das lutas que envolveram a conquista da escola e do assentamento demonstrou-se bastante presente e foi explicitado nos relatos dos jovens entrevistados ${ }^{14}$, como também na entrevista com a vice-diretora ${ }^{15}$. Preservar a identidade com o MST é uma preocupação exposta nos Projetos Político-Pedagógicos dos anos de 2000 e 2009, explicitada pelo vínculo com as matrizes pedagógicas do Movimento; a organização do trabalho pedagógico vislumbrando a articulação trabalho e educação, com espaços e momentos para o estímulo à auto-organização dos estudantes; a realização de um processo avaliativo que inclui os estudantes, denominado de Conselho de Classe Participativo; a busca por possibilitar uma formação nas diferentes dimensões humanas, desenvolvendo projetos educativos com manifestações culturais e artísticas, com grupos de teatro, coral, percussão, dança, entre outros.

Segundo dados fornecidos pela secretaria da escola em 2010, havia um total de 452 alunos, todos residentes no assentamento ${ }^{16}$. Destes, 419 recebiam subsídio financeiro do Bolsa Família ${ }^{17}$, recurso que vinha influenciando na permanência dos jovens no assentamento ao menos até o término do nível médio da escolarização. Em percentuais, significa que aproximadamente 93\% dos estudantes estavam nessa condição, evidenciando limites nas condições de vida dos assentados.

Especificamente sobre o Ensino Médio, destacamos que foi implantado gradativamente e a primeira turma concluiu em 2001. A partir de 2005, houve a criação do Curso de Formação de Docentes, profissionalizante em nível médio, com a formatura da primeira turma em 2008.

\section{Conhecimento, trabalho e educação na formação dos jovens}

O PPP (2009) destaca um diagnóstico das problemáticas enfrentadas que limitam a possibilidade de apreensão dos conteúdos pelos educandos, trazendo dados relevantes para se compreender a situação do Colégio Iraci no que diz respeito a essa questão. A condição de estradas precárias, que levam à ausência

14 Conforme depoimentos de nove jovens em entrevista concedida à autora em 08/07/2010.

15 Entrevista concedida à autora em 08/07/2010.

16 À exceção de um número muito reduzido, menos de $01 \%$ dos jovens, que moram na sede de Rio Bonito do Iguaçu e vão à escola para cursar o profissionalizante.

17 Programa assistencial do governo federal de transferência de renda a famílias em situação de pobreza ou extrema pobreza. Para detalhes, verificar página na internet do Ministério de Desenvolvimento Social e Combate à Fome, <http://www.mds.gov.br/bolsafamilia $>$. 
dos alunos na escola, a falta de livros, rotatividade dos professores, subutilização dos laboratórios, entre outros exemplos, retratam, de certa forma, a situação das escolas públicas brasileiras.

Os anos 1990 e a reestruturação produtiva do capitalismo trouxeram o desmonte do ensino público com a falta de materiais pedagógicos, a política da contratação temporária dos educadores e, portanto, uma permanente rotatividade, entre outros. O resultado é a existência de escolas públicas com inúmeras fragilidades no que diz respeito às condições materiais e humanas, tanto no campo quanto na cidade.

Refletir sobre o Colégio Iraci, uma escola de assentamento, localizada em um pequeno município paranaense, leva à associação dos condicionantes das políticas adotadas com o agravante da condição específica da oferta de educação no campo, posto que, ao longo da história brasileira, as políticas e programas governamentais privilegiaram o contexto urbano. (CALAZANS, 1993; LEITE, 1999). Milton Santos (2003, p. 148-149) auxilia no entendimento dessa situação, não perdendo de vista a concepção das relações indissociáveis campo-cidade. Afirma o autor que há uma vantagem estrutural histórica da cidade, decorrência do processo de expansão do capital. "A urbanização capitalista é o resultado da especialização capitalista do espaço total, mas não é forçosamente condição suficiente para reproduzir esta especialização no interior do país." O acesso aos bens e serviços é decorrência da urbanização capitalista, que ocorre centralmente nas cidades maiores, como demanda do próprio capital. Coloca-se a necessidade da luta permanente pela ampliação das conquistas para além do acesso à terra e ao prédio escolar, como apontado no PPP (2009) e pela vice-diretora ${ }^{18}$ do Colégio Iraci.

A condição de trabalho dos educadores, com contratos temporários, poucos momentos de formação, de planejamento individual e coletivo, são limitadores de uma prática pedagógica que alcance o máximo de suas possibilidades no processo de socialização do conhecimento. Articulada a estas questões, a formação inicial dos educadores é deficitária, não considera as problemáticas da realidade, incluindo as que dizem respeito às relações campo-cidade e, em muitos casos, não garante uma sólida formação nem no âmbito dos conhecimentos específicos de sua área de atuação. Acerca das condições materiais que determinam a educação no Brasil, o que inclui as escolas do MST, D’Agostini afirma haver a

[...] evidência de que os professores das escolas do Movimento têm uma formação extremamente deficitária, precária, aligeirada [...] uma base

18 Entrevista concedida à autora em 08/07/2010. 
teórica muito frágil adotada pela maioria das universidades brasileiras, além da falta de conhecimentos escolares específicos (escola sem conteúdos clássicos herdada da efetivação da Escola Nova no Brasil), pedagógicos e filosóficos para dar conta de uma proposta tão complexa. (D’AGOSTINI, 2011, p. 167).

Expressão dessa problemática encontra-se na subutilização do laboratório de ciências/química no Colégio Iraci, que, "[...] apesar de dispor de um bom espaço e de instrumentos para as aulas práticas, pouco é utilizado devido aos encaminhamentos feitos pelos educadores e por não possuirmos um técnico de execução". (PPP, 2009, p. 20). O laboratório é um espaço educativo que tem o intuito de permitir a elaboração de experiências diversas, no sentido de fortalecer e ampliar aprendizados sobre os fenômenos químicos, biológicos que perfazem a vida e auxiliam na concretização da relação teoria e prática. Nesse sentido, Araújo (2007) argumenta sobre a exigência atual aos trabalhadores do campo de apreensão de conhecimentos para compreender formas de dominação presentes no processo produtivo do campo na atualidade.

No que concerne ao ensino tecnológico, Marx (1982, p. 84) define nas "Instruções aos delegados" o que entende por "instrução tecnológica", concebendo-a como aquela que "[...] transmite os princípios gerais de todos os processos de produção e, simultaneamente, inicia a criança e o jovem no uso prático e manejo dos instrumentos elementares de todos os ofícios".

Entra em cena a importância do aprendizado dos progressos da "moderna ciência da tecnologia", que revolucionou a base técnica da produção com o advento da maquinaria, e continua a revolucionar constantemente, trazendo, ao mesmo tempo, o avanço nos processos de produção, com suas modificações na divisão do trabalho, e a ameaça constante da impossibilidade de o trabalhador vender sua força de trabalho. Mais que isso, na situação atual identificamos, assim como Mészáros (2007), um momento de "produção destrutiva" que precisa ser enfrentado sob a inviabilidade de existência dos recursos naturais e, portanto, da própria vida humana.

Um jovem entrevistado na pesquisa ${ }^{19}$, que morava em Joinville-SC e teve seu primeiro emprego numa indústria de ônibus, trabalhando na pintura de cabines, afirmou a importância dos conhecimentos de Química e de Matemática para efetuar suas atividades na composição das tintas. Pôde compreender o "porquê de estudar Química" na escola, conteúdo que é "focado no Ensino Médio" e era "obrigado a relembrar no trabalho o que tinha aprendido". 
Os depoimentos dos egressos indicaram a necessidade da utilização do laboratório como espaço educativo relevante na apropriação do conhecimento. Questionados sobre que conteúdos trabalhados nas disciplinas foram ou ainda são importantes na vida deles, dois egressos trouxeram importantes relatos que demonstram diferenças em relação à socialização do conhecimento no Colégio Iraci.

O primeiro ${ }^{20}$ é de uma jovem que vivenciou um momento marcante em sua formação, no qual houve a utilização do laboratório como fruto de um processo de aprendizagem, que buscou articular conhecimentos próximos ao contexto de vida dela com os conhecimentos universais. O outro depoimento ${ }^{21}$ reiterou a importância do laboratório como um espaço de articulação teoria-prática, todavia a partir da impossibilidade de vivenciá-la na formação.

Para a escola alcançar o que se propõe há vários fatores, entre eles a necessidade de existirem educadores comprometidos; uma estrutura mínima necessária, oferecendo condições de que um laboratório se torne espaço efetivo de aprendizagem; além de que os professores precisam ter uma formação qualificada. Esses são condicionantes que interferem na formação dos jovens e, por isso, são impositivos da necessidade da luta para garantir a efetivação do acesso ao conhecimento acumulado, tão caro à classe trabalhadora.

Os jovens também se deparavam com dificuldades de acesso à escola, o que acarretava o não cumprimento da exigência mínima legal das 200 horas anuais previstas pela legislação nacional para a Educação Básica, ainda que oficialmente isso não se coloque ${ }^{22}$. Além das ausências pelas más condições de acesso e distância da escola da vida, o desinteresse no estudo era identificado pelas famílias e associado às poucas oportunidades de trabalho. No PPP (2009) estava exposto que havia uma preocupação de se conectar com as problemáticas da vida dos jovens no campo, porém, como também constava do texto, isso ainda se encontrava no plano do discurso.

Percebemos que, concretamente, a articulação entre a escola e a vida ocorria, em alguns momentos, por uma acepção negativa dos jovens acerca da instituição escolar burguesa, em sua forma/conteúdo, como um espaço sig-

20 Entrevista concedida à autora em 08/07/2010.

21 Entrevista concedida à autora em 08/07/2010.

22 O Marco Operacional do PPP (2009) traz alternativas para enfrentar a problemática das chuvas, longas distâncias, transporte e faltas propondo tarefas à distância, que precisam ser planejadas coletivamente e com antecedência entre os professores, bem como combinadas com os educandos. Configuram-se em atividades de pesquisa, almejando a organização pessoal e autoformação, a serem avaliadas e reencaminhadas mensalmente, compondo o planejamento anual dos educadores. A previsão e planejamento são essenciais, na medida em que a maioria dos educandos não dispõe de materiais de pesquisa em suas casas, tendo a escola que viabilizá-los. 
nificativo para os mesmos. Além disso, pelas dificuldades na socialização do conhecimento, pela defasagem no acesso aos bens conquistados pela humanidade e por estar distanciada da atualidade da existência dos jovens.

A matriz curricular do Ensino Médio tinha a carga horária de cada disciplina dividida o mais igualitariamente possível, pela compreensão de que não havia supremacia de uma disciplina em detrimento de outras. Evidencia-se a importância dada a disciplinas que historicamente são percebidas como menos significativas no currículo escolar, tais como Educação Física e Artes. Demonstra-se coerência com os princípios de uma formação mais ampla, para as diferentes dimensões humanas. A questão que permaneceu é de que forma essas disciplinas eram trabalhadas a fim de que fosse efetivada essa formação, o que dependia do encaminhamento dado pelos professores.

Por outro lado, a matriz curricular do curso de Formação de Docentes nível médio não seguia a mesma linha por determinação do sistema estadual de ensino. Pela maneira como encontravam distribuídas as cargas horárias, havia a prevalência da Língua Portuguesa e da Matemática. Explicita-se a tensão entre buscar avançar, mas, a partir da situação existente, com condicionantes. Além disso, destaca-se a questão da profissionalização precoce dos jovens trabalhadores, que acabam por serem prejudicados na socialização dos conhecimentos gerais em detrimento dos profissionais.

O estágio, obrigatório para o Curso de Formação de Docentes - nível médio era a possibilidade do contato com o mundo que cerca os jovens. Assim, ele forçava a ampliação das relações a serem estabelecidas durante a formação de nível médio, afirmando o trabalho como eixo do processo formativo. A vinculação com o MST era facilitada pela necessidade de ter que sair do âmbito circunscrito à escola. Esta, por sua vez, parece que vinha conseguindo potencializar esse elemento para avançar na inter-relação teoria-prática na formação dos jovens.

A articulação entre o trabalho, a ciência e a cultura tem sido o pilar fundamental na defesa de um projeto de Ensino Médio unitário. Para Ramos,

Na construção de novas perspectivas para o ensino médio unitário - como momento histórico da formação de sujeitos individuais e coletivos, que congrega em si a síntese do diverso -, o trabalho, a ciência e a cultura são princípios estruturantes e devem ser resgatados como meio para a compreensão e a transformação do mundo atual. (RAMOS, 2004, p. 51).

Essas dimensões da prática social são concebidas da seguinte forma: o trabalho em seu duplo caráter, enquanto manifestação do próprio ser humano, 
realização humana e como expressão do modo de produção capitalista; a ciência, como os conhecimentos mais avançados que fundamentam as técnicas, que geram o avanço produtivo em sua inerente contradição entre capital e trabalho, fundada nas relações sociais de produção capitalista; e a cultura, como bens da humanidade nas suas diferentes formas de criação, símbolos, representações, valores éticos e estéticos. (FRIGOTTO; CIAVATTA, 2004; RAMOS, 2006).

Ao abordar a união ensino e trabalho, Manacorda (2000) alerta para o fato de que não se constitui em um vínculo com fins didático-pedagógicos. O trabalho é identificado com a própria essência do homem e, nesse sentido, transcende qualquer recurso meramente didático. Assim, o trabalho associado ao ensino só pode ser conteúdo e método para formar o homem omnilateral, se esta união ocorrer entre ensino e produção, caracterizando-se como "[...] inserção real no processo produtivo social, vínculo entre estruturas educativas e estruturas produtivas". (MANACORDA, 2000, p. 55).

Além disso, Marx, nas "Instruções aos delegados" (MARX, 1982), bem como n'“O Capital” (MARX, 2010), coloca como tarefas da educação o ensino intelectual, a educação física/ginástica e o ensino tecnológico. Ainda que não possamos discriminar o que significariam os conteúdos específicos de tais ensinos, compreendemos que eles abarcam os conhecimentos produzidos pela humanidade nas diferentes dimensões da vida.

Articulados ao trabalho, como atividade vital, tais conhecimentos precisam ser apreendidos pelas crianças e jovens porque os ajudam a compreender criticamente a atualidade histórica do capitalismo, que possui o trabalho alienado como sua expressão. Entendemos que associar trabalho e educação traz elementos formativos para a compreensão da forma histórica em que vivemos, sob a alienação humana. Permite, além disso, vivenciar experiências que busquem romper com o existente, pela cogestão dos estudantes nos processos educativos e também pela aproximação com a militância e lutas sociais, que são para além da escola, mas podem se articular a ela. Ainda que fique num plano parcial, são experiências que permitem, ao menos, "disputar" a formação da juventude no interior da escola capitalista, como afirma Freitas (2011).

Ainda no Curso de Formação de Docentes - nível médio, a formação geral ocorria de forma aligeirada e fragmentada, como apontaram os relatos das egressas $^{23}$, fazendo com que não tivessem condições qualitativas de enfrentarem o Exame Nacional do Ensino Médio (ENEM), menos ainda de prestarem vestibular, dificultando o prosseguimento dos estudos. A Educação Profissional, mesmo que articulada ao Ensino Médio, limita os jovens da classe trabalhadora, que acabam por terem poucas chances de avançarem em seus estudos, sendo

23 Entrevista concedida à autora em 08/07/2010. 
penalizados por não poderem dedicar-se integralmente aos estudos. Constituem-se, em grande parte, trabalhadores-estudantes, como afirma Frigotto (2005).

Encontramos argumentações para compreender como a perspectiva de Ensino Médio integrado, assumida por Frigotto, Ciavatta e Ramos (2005) como a "travessia contraditória", faz sentido mediante as necessidades de reprodução impostas aos jovens da classe trabalhadora que, se de um lado têm o direito ao acesso à educação de nível médio, de outro precisam se inserir no sistema produtivo para garantir sua existência.

Entretanto, o que constatamos foi o fato de que apenas cinco jovens, do total de 24 egressos do curso de Formação de Docentes dos anos 2008 e 2009, estavam trabalhando como estagiárias em escolas, atuando na área de sua formação. A situação de desemprego está colocada e as expectativas com o curso não podem ser infladas, uma vez que ter a formação não significa muito, como constatou Alves (2008). O que ficou explicitado foi uma demasiada expectativa dos egressos do curso de Formação de Docentes, fato que demonstra, de certa forma, a distância do processo formativo da atualidade do trabalho docente e em geral.

A vice-diretora ${ }^{24}$ afirmou que os limites acerca da apropriação do conhecimento dos estudantes do Ensino Médio, bem como o afastamento da realidade social, além de outros, têm sido problematizados pela coordenação pedagógica e direção, apoiados por algumas famílias e militantes do MST que o acompanham. Constatamos que haviam espaços planejados e vivências realizadas que forçavam a socialização do conhecimento a partir de uma articulação com algo vinculado à realidade social dos jovens, conferindo significado à formação, como exposto por uma das jovens entrevistadas ${ }^{25}$. Contraditoriamente, existiam espaços e momentos vividos no Colégio que fragilizavam a socialização dos conteúdos das disciplinas, o que acabava por não garantir a apropriação dos conhecimentos produzidos pela humanidade.

\section{Considerações}

A fragilização da socialização do conhecimento nas escolas do MST é uma questão presente nos estudos de Araújo (2007), Dalmagro (2010) e Torres-Rego (2011), entre outros. Entendemos que este é um grande limite da escola pública 
no Brasil, indicado por D'Agostini (2011), como também reflexo da configuração da educação de massas como uma das mais importantes indústrias no século XXI, de acordo com Silver (2005). As escolas do MST, estando em sua maioria sob a tutela do Estado, emergindo justamente como processo contraditório na luta entre trabalho e capital, não ficam imunes a esse contexto.

A luta por escola exercida pelo MST exige uma articulação maior no plano do enfretamento às mazelas da educação pública no país, passando pela associação com as lutas dos sindicatos de professores. Silver (2005, p. 117-120) afirma que os "[...] trabalhadores da educação (professores) são essenciais para o processo de acumulação de capital no século XXI", o que lhes confere um poder de barganha considerável, explicado pela "[...] quase imunidade do setor de educação às soluções espaciais e tecnológicas".

A permanência de um quadro de professores, bem como a garantia de uma formação continuada, que trabalhe com os princípios assumidos pelo Colégio Iraci, são essenciais para avançar na apropriação dos conhecimentos dos jovens. Até porque a própria proposta está em movimento, sendo repensada e reencaminhada para dar conta dos desafios que se colocam. Em 2010, iniciou-se na escola um processo de reorganização curricular. Acompanhando as discussões mais recentes do MST, os professores construíram um inventário da realidade a partir do qual foram elaborados complexos de estudo ${ }^{26}$, que seriam o ponto de partida para a reestruturação do planejamento das disciplinas.

Na perspectiva de Freitas (2011, p. 122), o “[...] conhecimento veiculado pela escola interessa à classe trabalhadora, porém não ocorre o mesmo com as relações sociais que permeiam este conhecimento". Nesse sentido, ele é entendido como um meio. $\mathrm{O}$ acesso ao conhecimento não é diletantismo, e sim a busca por ter condições de construir uma nova sociedade no interior de suas contradições sociais.

Imputar somente para a escola a incapacidade de alcançar a articulação entre escola e atualidade é não atentar para o que Mészáros (2006) afirma em relação à crise vivida na educação, sendo a escola apenas a ponta do iceberg. Dessa forma, não é possível à mesma a resolução da contradição central do capitalismo, entre o capital e o trabalho, que se manifesta na divisão entre o trabalho intelectual e o manual em nossa sociedade. Esta divisão está na vida, não sendo possível à escola resolvê-la. Precisa, antes, refletir sobre ela, apreendê-la como expressão do mundo em que vivemos.

26 O inventário da realidade, como ponto de partida para a elaboração dos complexos de estudo estão fundamentados nas experiências soviéticas, pós-revolução de 1917, em que se tentou reestruturar a educação/instrução russa, principalmente a partir das elaborações de Pistrak. Luiz Carlos de Freitas $(2009,2010)$ vem contribuindo com o MST e ajudando a formular os inventários e complexos em algumas escolas vinculadas ao MST. 
A formação ocorre a vida inteira, caracterizando-se como continuada ou “autoeducação de iguais", como trata Mészáros (2005). Esta só é plenamente possível se as estruturas e instituições estiverem fundadas na sociabilidade da emancipação humana. No entanto, a educação do presente pode ser germe do futuro se contribuir para "uma mudança radical cultural", que forme para o novo, tornando crítica e consciente aos seres humanos o atual estado das relações sociais de produção, nas suas contradições e problemáticas.

É a determinação da necessidade de ter as condições sociais para ter ensino correspondente e, ao mesmo tempo, um ensino para mudar as condições, como nos traz Marx (2004). É nessa contradição que os sujeitos que direcionam a escola se movem, não saem ilesos, ora se aproximando, ora se distanciando da perspectiva de uma educação com o intuito de colaborar na formação para a emancipação humana, como também destacam Machado (2003) e Araújo (2007) e, em nosso caso, para a formação de jovens conectados com as lutas sociais da classe trabalhadora. Por outro lado, identificamos que o Colégio Iraci não se furta a buscar construir o novo, mediante as formas do velho, ainda que isso implique em situações de incoerências teóricas e práticas.

\section{REFERÊNCIAS}

ALVES, Natalia. Juventudes e inserção profissional. Lisboa: Educa, 2008.

ARAUJO, Maria Nalva Rodrigues. As contradições e as possibilidades de construção de uma educação emancipatória no contexto do MST. Tese (Programa de Pós-Graduação em Educação) - Universidade Federal da Bahia, Salvador, 2007.

CALAZANS, Maria Julieta Costa. Para compreender a educação do estado no meio rural: traços de uma trajetória. In: THERRIEN, Jacques; DAMASCENO, Maria Nobre (Coords.). Educação e escola no campo. Campinas: Papirus, 1993.

CALDART, Roseli S. Os movimentos sociais e a construção da escola (do sonho) possível. Contexto \& Educação, Ijuí: Ed UNIJUí, Ano X, v. 1, n. 41, 1986.

CALDART, Roseli S.; SCHWAAB, Bernadete. A educação das crianças nos acampamentos e assentamentos. In: GÖERGEN, Frei Sérgio A.; STÉDILE, João P. Assentamentos: a resposta econômica da reforma agrária. Petrópolis: Vozes, 1991.

D'AGOSTINI, Adriana. A importância da teoria para a construção da escola do MST. In: VENDRAMINI, Célia R.; MACHADO, Ilma Ferreira (Orgs.). Escola e movimento social: a experiência em curso no campo brasileiro. São Paulo: Expressão Popular, 2011.

DALMAGRO, Sandra L. A escola no contexto das lutas do MST. Tese (Doutorado em Educação) - Universidade Federal de Santa Catarina, Florianópolis, 2010. 
FREITAS, Luiz Carlos de. Formação de quadros técnicos ou formação geral? Riscos de um falso dilema para o MST. In: VENDRAMINI, Célia R.; MACHADO, Ilma Ferreira (Orgs.). Escola e movimento social: a experiência em curso no campo brasileiro. São Paulo: Expressão Popular, 2011.

FREITAS, Luiz Carlos de. A escola única do trabalho: explorando os caminhos de sua construção. In: CALDART, Roseli S. (Org.). Caminhos para transformação da escola: reflexão desde práticas da licenciatura em educação do campo. São Paulo: Expressão Popular, 2010.

FREITAS, Luiz Carlos de. A luta por uma pedagogia do meio: revisitando o conceito. In: PISTRAK, Moisey (Org.). A escola-comuna. Trad. Luiz Carlos de Freitas e Alexandra Marenich. São Paulo: Expressão Popular, 2009.

FREITAS, Luiz Carlos de. Ciclos, seriação e avaliação: confronto de lógicas. São Paulo: Moderna, 2003.

FRIGOTTO, Gaudêncio. Concepções e mudanças no mundo do trabalho e o Ensino Médio. In: FRIGOTTO, Gaudêncio; CIAVATTA, Maria. (Orgs.). Ensino Médio integrado: concepções e contradições. São Paulo: Cortez, 2005.

FRIGOTTO, Gaudêncio; CIAVATTA, Maria. A busca de articulação entre trabalho, ciência e cultura no Ensino Médio. In: FRIGOTTO, Gaudêncio; CIAVATTA, Maria (Orgs.). Ensino Médio: ciência, cultura e trabalho. Secretaria de Educação Média e Tecnológica. Brasília: MEC, SEMTEC, 2004.

FRIGOTTO, Gaudêncio; CIAVATTA, Maria; RAMOS, Marise N. A gênese do Decreto n. 5154/2004: um debate no contexto controverso da democracia restrita. In: FRIGOTTO, Gaudêncio; CIAVATTA, Maria; RAMOS, Marise N. (Orgs.). Ensino Médio integrado: concepções e contradições. São Paulo: Cortez, 2005.

LEITE, Sérgio Celani. Escola rural: urbanização e políticas educacionais. 2. ed. São Paulo: Cortez, 1999.

MACHADO, Ilma. A organização do trabalho pedagógico em uma escola do MST e a perspectiva de formação omnilateral. Tese (Doutorado em Educação) - Universidade Estadual de Campinas, Campinas, 2003.

MANACORDA, Mario Alighiero. Marx e a pedagogia moderna. São Paulo: Cortez, 2000.

MARX, Karl. O capital: crítica da economia política. Rio de Janeiro: Civilização Brasileira, 2010. Livro 1, v. 1, VI-XIII.

MARX, Karl. Exposição nas seções dos dias 10 e 17 de agosto de 1869 no Conselho Geral da AIT. In: MARX, Karl; ENGELS, Friedrich. Textos sobre educação e ensino. São Paulo: Centauro, 2004.

MARX, Karl. Instruções para os delegados do conselho geral provisório. As diferentes questões. In: MARX, Karl. Obras escolhidas. Moscovo: Progresso; Lisboa: Avante!, 1982. 
MÉSZÁROS, István. O desafio e o fardo do tempo histórico: o socialismo no século XXI. São Paulo: Boitempo, 2007.

MÉSZÁROS, István. A alienação e a crise da educação. In: MÉSZÁROS, István. $A$ teoria da alienação em Marx. São Paulo: Boitempo, 2006.

MÉSZÁROS, István. A educação para além do capital. São Paulo: Boitempo, 2005.

MONTEIRO, Gilmar. Colégio Iraci Salete Strozake: conquistando o latifúndio do saber. In: ITERRA. Alternativas de escolarização dos adolescentes em assentamentos e acampamentos do MST. Cadernos do ITERRA, Veranópolis, Ano III, n. 8, nov. 2003.

PPP. Projeto Político-Pedagógico. Colégio Estadual Iraci Salete Strozak, Rio Bonito do Iguaçu, 2009.

PPP. Projeto Político-Pedagógico. Colégio Estadual Iraci Salete Strozak, Rio Bonito do Iguaçu, 2000.

RAMOS, Marise N. Concepção do Ensino Médio integrado è Educação Profissional. Texto para Seminário de Ensino Médio da Superintendência de Ensino Médio da Secretaria de Educação do Estado do Rio Grande do Norte, em Natal e Mossoró, agosto de 2006.

RAMOS, Marise N. O projeto unitário de Ensino Médio sob os princípios do trabalho, da ciência e da cultura. In: FRIGOTTO, Gaudêncio; CIAVATTA, Maria. (Orgs.). Ensino Médio: ciência, cultura e trabalho. Secretaria de Educação Média e Tecnológica. Brasília: MEC, SEMTEC, 2004.

RODRIGUES, Marli de Fátima. Da luta pela educação à educação na luta: memória, narrações e projetos dos assentados e professores do MST na Fazenda Giacometi. Dissertação (Mestrado em Educação) - Universidade Federal Fluminense, Niterói, 1999.

SANTOS, Milton. Espaço e dominação: uma abordagem marxista. In: SANTOS, Milton. Economia espacial: críticas e alternativas. São Paulo: Edusp, 2003.

SAPELLI, Marlene L. S. Ensino profissional no Paraná: aspectos históricos, legais e pedagógicos. Guarapuava: Unicentro, 2008.

SHIROMA, Eneida O.; MORAES, Maria Célia M.; EVANGELISTA, Olinda. Política educacional. Rio de Janeiro: DP\&A, 2004.

SILVER, Beverly J. Forças do trabalho: movimentos trabalhistas e globalização desde 1870. São Paulo: Boitempo, 2005.

TORRES-REGO, Thelmely. A formação técnico-profissional em agroecologia no MST/ $S P$. Dissertação (Mestrado em Educação) - Universidade Federal de Santa Catarina, Florianópolis, 2011.

Texto recebido em 11 de fevereiro de 2015. Texto aprovado em 27 de fevereiro de 2015. 
